\title{
Music, Meaning and Culture
}

\author{
RICHARD WIDDESS \\ School of Oriental and African Studies, University of London, UK
}

\begin{abstract}
This paper situates musical meaning in culture, addressing music as social symbol and as ongoing process of meaning creation. Three examples of nonWestern musical practice are used to illustrate the embedding of musical meaning in cultural context. The performance of an Australian Aboriginal song is shown to exemplify the interdependence of song style and social structure as a matrix for the emergence of cultural meanings; an example of North Indian performance is adduced to demonstrate the multi-layered nature of meaning as embodied in musical performance; and an example of collective festival performance from Nepal illustrates ways in which the structure of musical performance can mirror local cultural forms. Each of the three examples lends weight to the idea that music's meanings are often non-linguistic and reflect foundational schemas that are specific to the cultures from the musics are drawn.
\end{abstract}

Submitted 2012 January 6; accepted 2012 July 13.

KEYWORDS: meaning, culture, cultural model, foundational schema

ETHNOMUSICOLOGISTS have long held that the structures, practices and meanings of music are culturally determined; that understandings predicated on the music of one culture are therefore inadequate to account for music in other, still less all, cultures; and that the significance of music can only be understood in relation to specific cultural contexts. But what do we understand by "culture", and how does this concept relate to music?

Culture has been defined as "That complex whole which includes knowledge, belief, art, morals, law, custom, and any other capacities or habits acquired by man as a member of society" (Tylor, 1871); or more recently, as "That which needs to be known in order to operate reasonably effectively in a specific human environment" (Bloch, 1998: 4). According to this second definition, formulated by the cognitive anthropologist Maurice Bloch, culture is a form of knowledge, and thus depends on the operation of memory: cultural knowledge, like other types of memory, must be acquired, stored, and recovered.

In his book How we think they think (1998), Bloch went on to argue that cultural knowledge, or much of it, is acquired non-verbally, that is, by repeated observation and imitation without the intervention of explicit statements. Where language does play a part in transmission, the knowledge it encodes must be transformed by the learner back into non-linguistic form to be available for instantaneous recall, and this is done through repeated practice. In the example he gives of learning to drive, "only when they do not think about what they are doing in words are drivers truly experts" (1998:8). Bloch argues that the cognitive operations underlying complex and everyday tasks "not only are non-linguistic, but also must be non-linguistic if they are to be efficient" (1998:10). Non-linguistic here means both (a) not formulated in natural language, and (b) not language-like, that is, not governed by rules of linear succession such as are characteristic of linguistic grammars (ibid.); the complexities of cultural behaviour, he argues, must depend on some form of simultaneous parallel processing.

Bloch argues further that the reliance of anthropologists on the verbal explanations given them in the field by their interlocutors is misplaced, because such statements represent a transformation of cultural knowledge from non-linguistic into linguistic forms. The underlying structures of culture may be beyond the capacity of its bearers to formulate explicitly in language. Such structures, which he terms cultural models, may manifest themselves in a variety of different domains, and can be best discovered not by asking questions, but by participant observation, leading to the acquisition of expertise on the part of the investigator, who can then access his/her implicit knowledge through introspection.

This scenario is immediately recognisable to ethnomusicologists, for whom participant observation is an essential methodology. Through learning to sing or play music - a complex skill that is normally transmitted non-verbally — and by taking part in musical performances, the ethnomusicologist starts to become directly aware of the rich context of meanings that musical sound elicits for members of the society concerned. These can be located in relation to culture-specific 
concepts, functions, social and political dynamics and historical trajectories of music, as well as in embodied experience and metaphorical accounts of it.

This diversity of reference may seem to stretch the meaning of "meaning" almost to breaking point, and in ethnomusicological literature it is sometimes difficult to discern the difference between meaning and association or between meaning and function. But it is clear that musical meaning is not necessarily referential or affective (though it may be both), nor is it necessarily a process of communication of messages from performer to listener: performance may also, or instead, be the articulation of a meaningful state, in which those present participate in varying ways and degrees.

Cultural factors can be seen to interact in complex ways with the structural and stylistic features of music, to endow music's "floating intentionality" (to borrow Ian Cross's term) with specific, but often multi-layered and fluctuating meanings. Such meanings may be more precisely specified through channels other than the musical sound itself, such as lyrics, bodily movement, ritual actions, visual symbols etc. It is not clear how far structural features of music (such as scales, metrical structures or formal patterns) are implicated directly in the creation of cultural meaning. Even the ethnomusicologist Timothy Rice, whose classic study of Bulgarian folk music revealed musical performance practices to be deeply permeated with political and social meanings, admitted that "music, as a highly abstract, modeled practice with its own interior order and history, probably contains elements which resist social and cultural determination at a given moment and thus in some sense have an independent life of their own" (1994, p. 165). While this seems tantamount to an admission of musical autonomy, I'll suggest later that even apparently abstract musical structures can contain cultural meaning.

A further question is how far meaning is inherent in the style or sound of music or even in the mere fact of its performance-as it is inherent, for example, in musical instruments as symbolic artefacts, and in musicians as social symbols - and how far, on the other hand, performance is an ongoing process of meaning creation that is not complete until the end of the piece or performance. Clearly both kinds of meaning can operate simultaneously in the same music; musical meaning is thus a diverse and multi-layered phenomenon. I'll briefly explore these issues with reference to three examples, which illustrate just some of the ways in which cultural meaning can be constructed through musical performance.

\section{CASE 1: MA-YAWA WANGGA}

My first example is taken from the work of Allan Marett, of the University of Sydney, on Aboriginal song in North-west Australia (Marett, 2005). It is a ceremonial dance-song of the genre wangga, which I have re-transcribed here as an outline sketch in Figure 1.

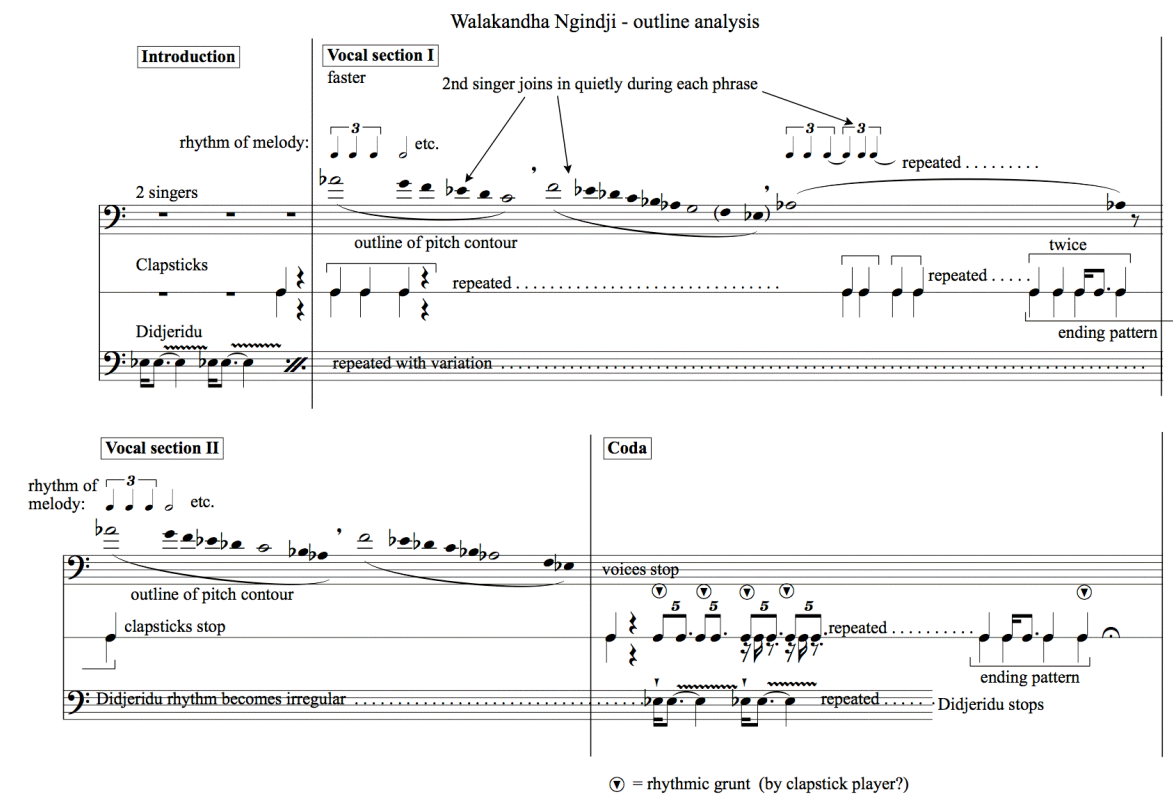

Fig. 1. An example of wangga performance (after Marett, 2005).

Wangga songs relate to deeply significant cultural beliefs about ancestor spirits and the ancestral lands that such spirits inhabit. Singing such songs is a jealously guarded privilege of group members because the cult of ancestors defines social identity. But this performance invokes two such identities, and in 
doing so creates a tension and reconciliation that is precisely the meaning of the performance. The song refers through its lyrics to the ancestors of the Marri-tjevin people who form the dominant Aboriginal population in the region where the song was recorded; it is a Marri-tjevin song. But the singer belongs to a different people, the Marri-ammu, who enjoy close social and ritual relations with the Marri-tjevin, but have different ancestors, different language, and different musical styles.

The singer, Maurice Ngulkur, begins his performance by singing the Marri-tjevin words in the style of a Marri-ammu song, in a typical Marri-ammu rhythmic mode framed by the rhythmic clapping of the clapstick players. Marett shows how the singer blends Marri-ammu and Marri-tjevin principles of composition in this performance. But having sung the song once in this style, he then sings it a second time (Figure 1, Vocal Section II) in the unmetered style typical of Marri-tjevin performances (without clapsticks). The reason that this aspect of the music is meaningful is that in the performance elicited and recorded by Marett from a Marri-ammu singer, the audience consisted of five Marri-tjevin songmen. This was the first song performed in the recording session, and it served to establish the singer's relationship with the audience. Marett writes: "The juxtaposition of a 'Marri-ammu' section I and a 'Marri-tjevin' section II mirrors that of the Marri-ammu and Marri-tjevin men who in this performance were sitting side by side, as well as the balancing of Marri-ammu and Marri-tjevin interests that occurs in wider social spheres" (2005, p. 149).

In this example music articulates a meaningful state, a state of social difference tempered by close interdependence. Indeed, Marett explains that the five songmen in the audience were all the sons of Marri-ammu mothers, and their mothers were all sisters; thus close bonds already united the singer and his audience, providing the grounds on which the singer could, so to speak, help himself to a Marri-tjevin song and transform it temporarily into a Marri-ammu song, something that in other contexts could be construed as misappropriation.

After analysing this performance, Marett comments: "One feature of Aboriginal music that continues to astound me is the amount of information that can be packed into a performance that lasts less than one minute" (2005, p. 152). The meaning of this information, however, only fully emerges once we are aware of the context that generated its performance.

\section{CASE 2. RĀG ŚRĪ}

The second case is from a recent article by Laura Leante, now at the University of Durham, on the meanings of musical performance in the North Indian classical music tradition (Leante, 2009). In that tradition, it is held that rāgas, melodic schemas that form the basis of composed songs and improvised performances, are meaningful entities, whose meanings are commonly discussed by performers in terms of visual images and/or affective responses. Performers, especially vocalists, typically gesture with one or both hands, both when performing, and when describing the images and meanings that they attribute to a rāga. Going beyond Bloch's separation of linguistic and non-linguistic forms of knowledge, Leante hypothesises that both musical and physical gestures express embodied affective meanings, and that similar meanings also emerge in the visual images that performers describe verbally. Reviewing performers' verbal comments about the rāga Śrī, Leante finds "a web of semantic possibilities" expressed through a limited variety of images:

"These include the depiction of Śrī as a person with authority and high status (such as a prince, a king, a hero or a saint); the association with a sense of being in a high location; a feeling of devotion and surrendering; and the idea of reaching out for something or of temporary separation."

Her diagram (Figure 2) shows how different performers each evoke one or more of these visual, affective or spatio-motor images. 


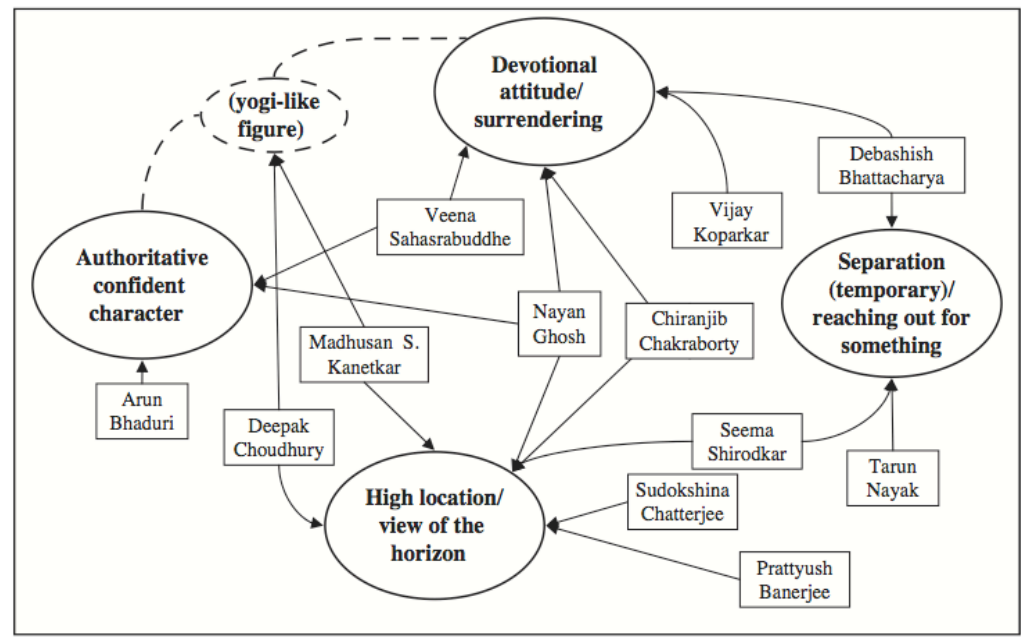

Fig. 2. Main concepts and images associated with Śrī rāg (circles) and the possible interconnections as emerging from the interviews with musicians (squares).

Similar meanings seem to be implied by musicians' physical gestures. The singer Veena Sahasrabuddhe, for example, describes her image of rāg Śrī as a confident, uncompromising, and experienced character. Leante finds the same qualities of 'firmness, confidence, and authority' in the hand, arm and head movements that this singer enacts in conjunction with a rising tritone slide from the flat second degree to the perfect fifth (Figure 3); this melodic gesture is unique to this rāg and is one of its identifying motives. Leante concludes that "Veena's arm (and head) movements in performance ... contribute to the expression of the meanings she attributes to the rāg". Leante concludes that "sound, gesture and imagery are three facets of a single process of meaning construction in music", an approach that seems to hold considerable promise for further research in this culture and perhaps others.

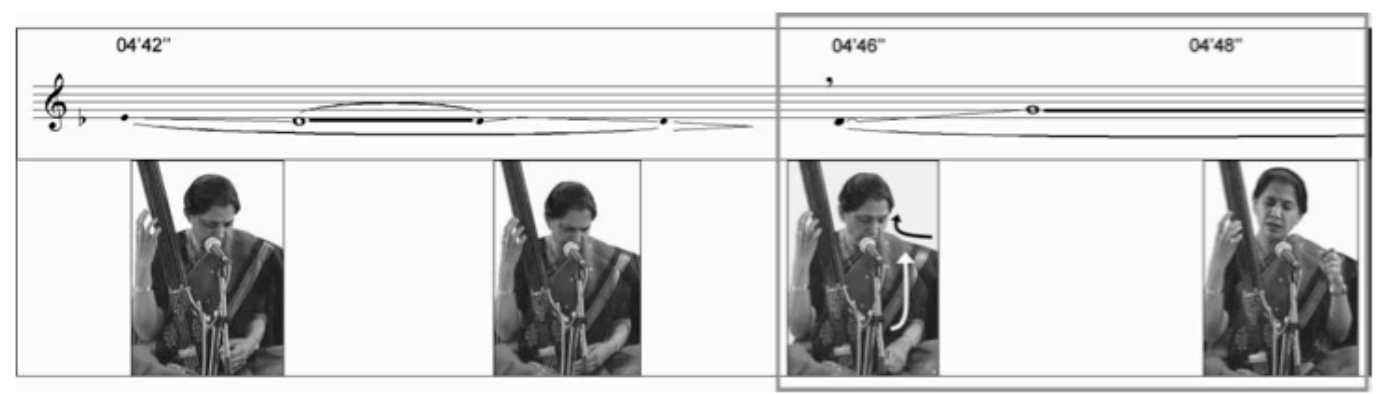

Fig. 3. Veena Sahasrabuddhe performing Śrī rāg (May 2003)—first occurrence of the Re-Pa slide

\section{CASE 3. GHĒTÃ̈IŚI}

My last example is from my own work on urban folk music in the town of Bhaktapur, in the Kathmandu Valley, Nepal (Widdess 2006). It is a percussion piece played on the drum $d h \tilde{\bar{a}}$, as accompaniment to a stick-dance called ghẽtãgiśi. This dance is performed only once a year, as part of a seasonal festival that combines elements of post-funerary ritual with satire and burlesque. Each group of dancers and musicians precede a tall bamboo pyramidal structure representing a family's deceased relative, which is paraded around the whole town along a circular processional route, taking about 3 hours. 

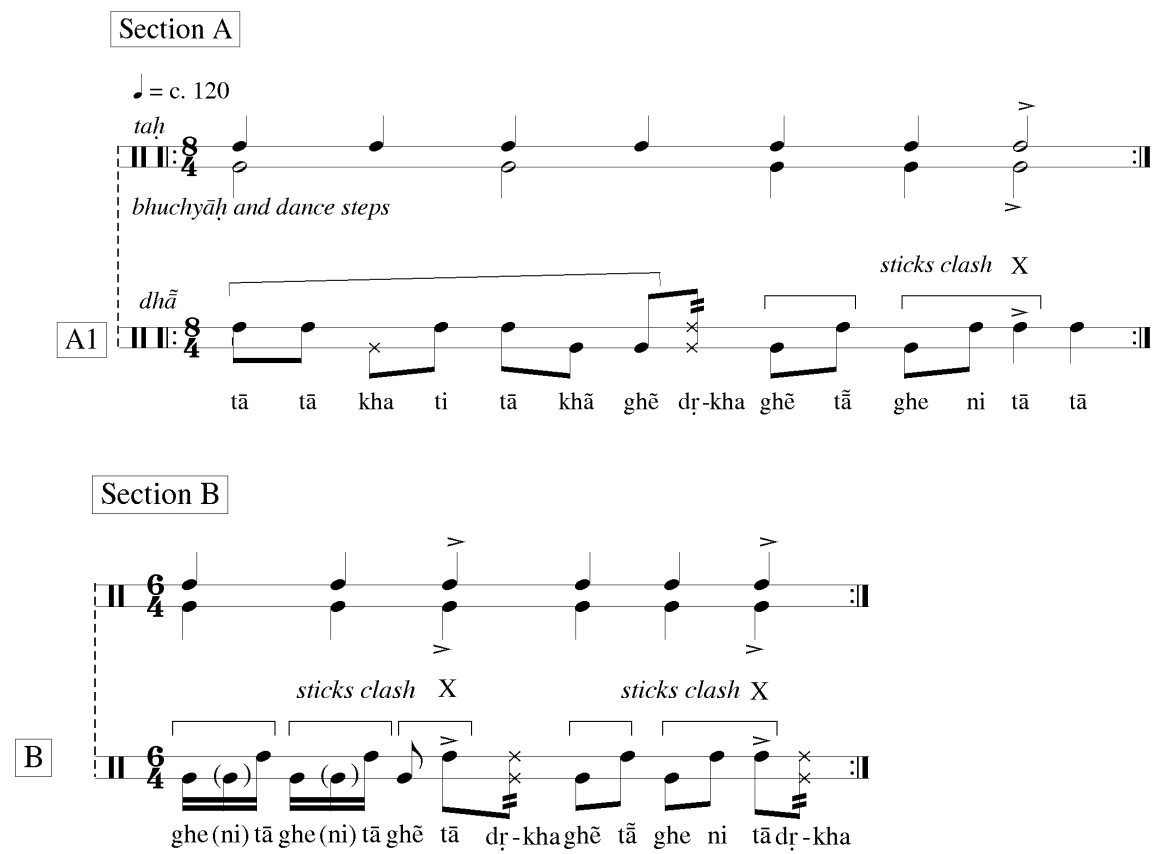

Fig. 4. Musical structure of the ghẽtãgiśi stick dance.

What interests me is the extent to which the structure of the music-which Rice suggested might be independent of meaning - can nevertheless be related to contextual meanings. In brief, the music consists of two sections, A and B, cyclically repeated, plus a short invocation which can occur at the beginning, in the middle of Section B, or at the end (see Figure 4). Section A has a slow 8-beat metre, Section B a fast 6-beat metre. These musical facts can be mapped onto contextual meanings as follows: - the drum rhythm of Section A, line 1, echoes a particular seasonal song, the words of which express affective meanings of the festival;

- Section A corresponds to a slow, walking dance, performed as the procession moves slowly down the narrow street, the dancers clashing sticks on the $7^{\text {th }}$ beat of the 8-beat rhythm;

- in Section B the dancers change to a vigorous dance on the spot, clashing sticks every $3^{\text {rd }}$ beat;

- changes from the slow 8-beat to the fast 6-beat pattern occur when the procession reaches a square, cross-roads or other space where many people are watching, to give the dancers an opportunity to display their energy and skill; or on reaching an important temple, in which case the B Section would lead into a performance of the invocation piece;

- the invocation piece is also played to mark the beginning and end of the procession, to honour the gods on whose benevolence a successful performance depends.

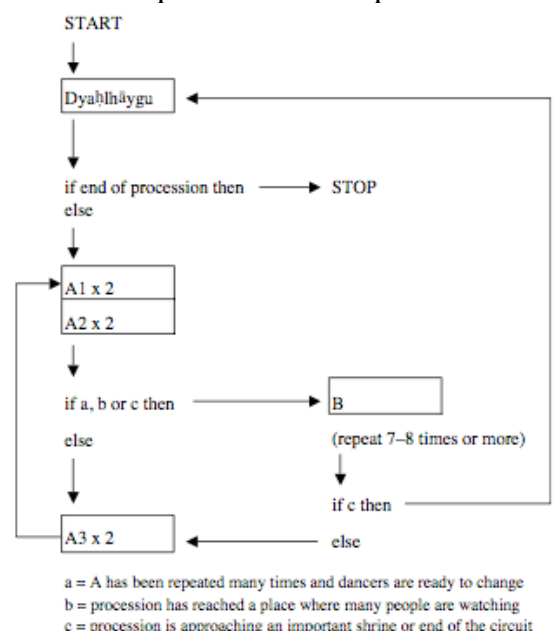

Fig. 5. The "production rules" of the the ghẽtã giśi stick dance.

The performance of this music can thus be represented as a route-map which is essentially circular (see Figure 5): starting from the invocation, one proceeds to the A section; this is repeated cyclically, but a diversion can be made into $\mathrm{B}$; this can lead either to a return to A, or back to the invocation, after 
which the whole process starts again. The circularity of the music thus mirrors the circularity of the processional route, a route that is not geometrically circular on the ground, but emerges as conceptually circular in local representations. Reasons for this circularity readily suggest themselves: clockwise circumambulation is a conventional Hindu-Buddhist method of worshipping a sacred object, in this case, the town of Bhaktapur itself; and by passing through all the main neighbourhoods of the town, the stick-dance procession involves all its inhabitants in a communal act of commemoration.

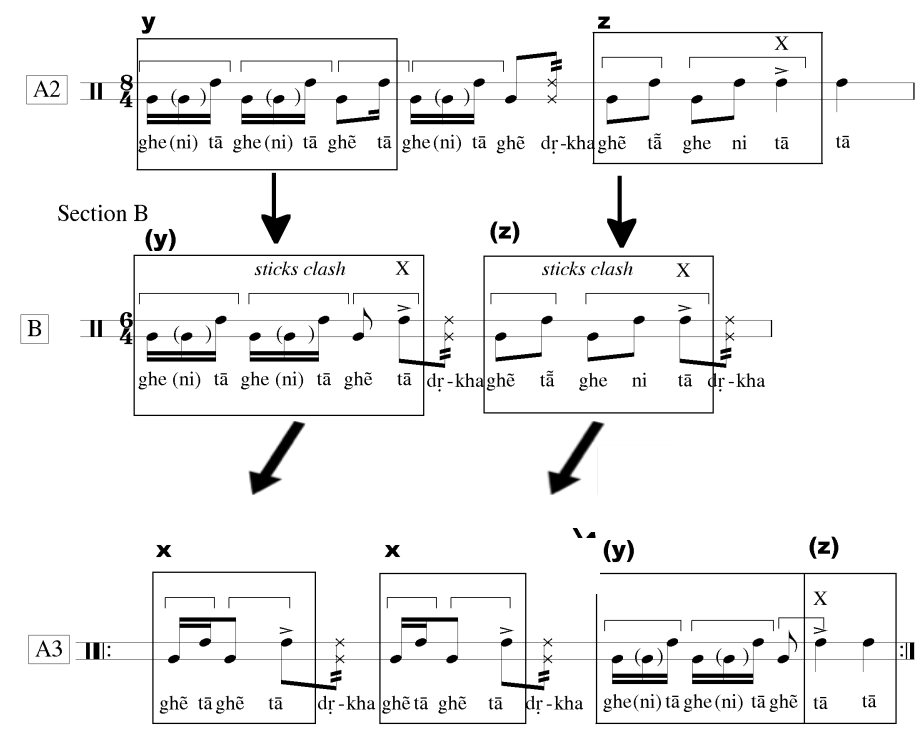

Fig. 6. Metrical and motivic compression in the ghêtãgiśi stick dance.

The cyclical, repetitive structure of performance reinforces this aspect of contextual meaning. But the music is also notable for elements of structural compression, within the A section, in the transition from A to B and back to A (see Figure 6), and in the invocation piece. Such compression is a typical feature of the local repertoire, and can be read as a sonic equivalent to other local cultural forms in which compression is apparent, for example architectural structures, including fountains and temples, or visual representations of the city as a set of concentric geometrical regions, of diminishing size as one approaches the centre. These visual forms in turn reflect the Hindu-Buddhist conceptualisation of the universe as a cosmic map or mandala, inhabited by deities of whom the most powerful resides in the smallest, central region (see Figure 7). Movement from the outer to the inner regions of structure thus involves compression and intensification, a process fully evident in the stick dance as one moves from the slow A section, through the shorter, faster B section to the invocation piece, which is short and fast, ends in an accelerating drum roll, and is explicitly dedicated to the invocation of divine power. 

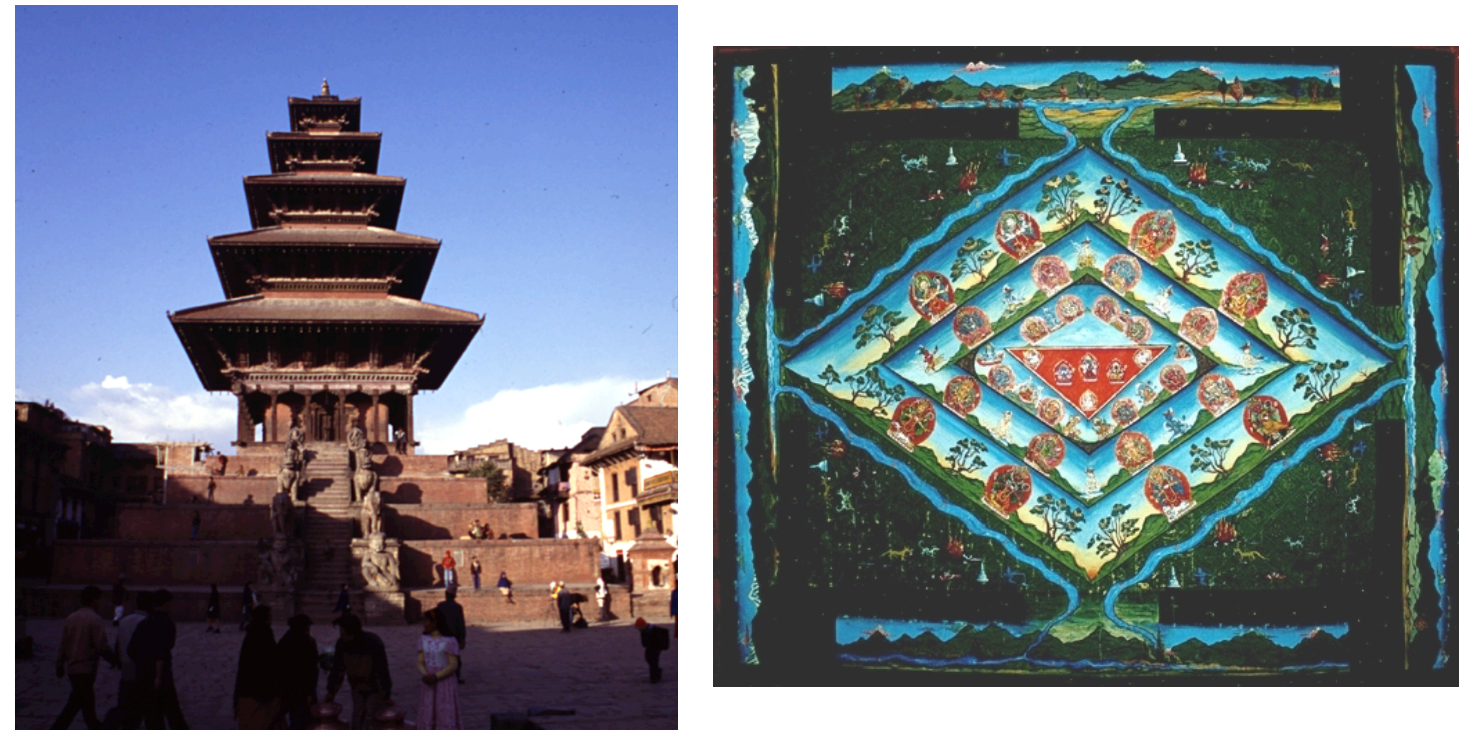

Fig. 7. Examples of cyclicality and compression in visual form in Bhaktapur.

Left, Nyatapola Temple (1702). Photo: R. Widdess. Right, Representation of Bhaktapur in form of a mandala. Courtesy G.-M. Wegner.

This isomorphism between musical, visual, and conceptual patterns is never verbally expressed, in my experience, as the "meaning" of the music. But we would not expect it to be, if Bloch is right in saying that cultural knowledge is non-linguistic. The isomorphism appears to be a "cultural model", a term used by cognitive anthropologists to represent "the structured nature of cultural knowledge" (Shore 1996, p. 45), drawing on the notion of "models" or "schemas" in cognitive psychology. Bloch, Shore and others give examples of cultural models that cross the boundaries of cultural and sensory domains, and give the name foundational schema to this phenomenon. My last example surely represents such a foundational schema in Hindu-Buddhist culture, to which profound meanings attach. Aboriginal songs and Indian rāgas also manifest schemas that extend beyond the sonic into the social, ideological and emotional domains. Although anthropologists rarely draw on music to illustrate their cultural analyses, the highly specialised, schematic structures of music, and their realisation through performance in context, seem to me to offer fertile ground for the discovery of cross-domain, non-linguistic cultural models and cultural meanings.

\section{REFERENCES}

Bloch, M.E.F. (1998). How we think they think: anthropological approaches to cognition, memory, and literacy. Boulder, Westview Press.

Leante, L. (2009). "The Lotus and the King: Gesture, Imagery and Meaning in a Hindustani rāg." Ethnomusicology Forum, Vol. 18, No. 2, pp. 185-206.

Marett, A. (2005). Songs, dreamings and ghosts: the wangga of North Australia. Middletown, Conn.: Wesleyan University Press.

Rice, T. (1994). May it fill your soul: experiencing Bulgarian music. Chicago: University of Chicago Press.

Tyler, E.B. (1871). Primitive culture. London: J. Murray

Widdess, R. (2006). Musical structure, performance and meaning: the case of a stick-dance from Nepal. Ethnomusicology Forum, Vol. 15, No. 2, pp. 179-213. 